\title{
Primary Infundibular Cystic and Infundibulo-Tuberal Cra- niopharyngioma: Report of Two Cases
}

\author{
Ayse Uzuner, Anil Ergen, Burak Cabuk, Ihsan Anik and Savas Ceylan* \\ Department of Neurosurgery, Pituitary Research Center, Kocaeli University, Kocaeli, Turkey

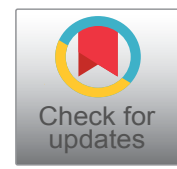

*Corresponding author: Savas Ceylan, Department of Neurosurgery, Pituitary Research Center, Kocaeli University, Kocaeli, Turkey, Tel: +905326127983, Fax: 0262-303-75-75

\begin{abstract}
Craniopharyngiomas are benign but locally invasive tumors which are frequently located in the suprasellar region. Primary infundibular and infundibulo-tuberal craniopharyngiomas are rare because of their location and generally result in late diagnosis. Due to the unusual location, the chosen mode of treatment is very important for patient's recovery. With infundibular and infundibulo-tuberal lesions, two patients were referred to our clinic, one of them was not considered as craniopharyngioma as the primary diagnosis. Both masses were operated, removed totally and craniopharyngioma diagnosis was proven pathologically. The authors demonstrated surgically the infundibular origin of craniopharyngioma which is crucial for the understanding of growth pattern and total resection.
\end{abstract}

\section{Keywords}

Craniopharyngioma, Infundibulum, Infundibulo-tuberal craniopharyngioma, Endoscopic endonasal transsphenoidal approach

\section{Abbreviations}

MRI: Magnetic Resonance Imaging; CT: Computed Tomography; DI: Diabetes Insipidus; Acoma Complex: Anterior Communicating Artery Complex; $\mathrm{CH}$ And $\mathrm{OC}$ : Optical Chiasm; INF: Infundibulum; TM: Tumor; ME: Median Eminence; S: Stalk; PT: Pars Tuberalis; PD: Pars Distalis; PN: Pars Nervosa

\section{Introduction}

Craniopharyngiomas are rare, benign but locally invasive tumors which arise from squamous epithelial remnants of Rathke's pouch and can extend anywhere from nasopharynx to hypothalamus [1]. Although pathogenesis of craniopharyngiomas still have controversies, primary craniopharyngiomas are frequently located at suprasellar, sellar and infrasellar regions, ectopic locations such as sphenoid bone, nasopharynx, ethmoid sinus, corpus callosum, third ventricle and even pineal gland are reported as rare sites of tumor development [2]. Kassam and colleagues proposed a classification about suprasellar craniopharyngiomas to describe the anatomical relationship between the craniopharyngioma and the pituitary stalk-infundibulum [3]. This classification is helpful for deciding the best surgical approach for craniopharyngiomas. On the other hand, according to Pascual, et al. craniopharyngiomas can be classified as true suprasellar, infundibular, infundibulo-tuberal which developed primarily within the neural layer of the infundibulum or the pituitary stalk, where the median eminence is located, or primarily intra-third ventricle [4,5]. Retroinfundibular lesions according to Kassam's classification, are in fact infundibulotuberal tumors in Pascual scheme which are growing within the infundibulum and the tuber cinereum [5]. Primary infundibular and infundibulo-tuberal craniopharyngiomas are unusual and uncommonly early diagnosed until it expand to supra or parasellar region or develop the cystic component. Generally they present with endocrinologic disturbances, visual problems and with the expansion to infundibulo-tuberal area, they can have infundibulo-tuberal syndrome which is characterized by hypogonadism, obesityFröhlich syndrome, diabetes insipidus and somnolence $[6,7]$. Because of the lesion's location, the surgical treatment is very challenging and choosing the right

Citation: Uzuner A, Ergen A, Cabuk B, Anik I, Ceylan S (2021) Primary Infundibular Cystic and Infundibulo-Tuberal Craniopharyngioma: Report of Two Cases. Neurosurg Cases Rev 4:089. doi. org/10.23937/2643-4474/1710089

Accepted: November 16, 2021; Published: November 18, 2021

Copyright: (c) 2021 Uzuner A, et al. This is an open-access article distributed under the terms of the Creative Commons Attribution License, which permits unrestricted use, distribution, and reproduction in any medium, provided the original author and source are credited. 
surgical approach is very important for prevention of recurrence and loss of hypothalamic function $[8,9]$. With increasing experience, endoscopic endonasal approaches are more commonly used for resection of craniopharyngiomas because of its advantages. These advantages enable to understand the origin and growth pattern of these tumors.

In this study, we present a primary infundibular cystic and a infundibulo-tuberal craniopharyngioma cases which are surgically well demonstrated for their infundibular and tuberal origin by endoscopic endonasal transsphenoidal approach.

\section{Case 1}

A 35-year-old female presented with headache and visual problems for one year. Visual examination of the patient revealed bitemporal hemianopsia.

Magnetic resonance imaging (MRI) of the brain showed a mass lesion which was originating from infundibulum, had cystic components, measuring approximately $31 \mathrm{~mm}$ and extending to frontal lobe, suprasellar region and optic chiasm. It also showed intratumoral calcifications in Computed Tomography (CT).

The patient underwent endoscopic endonasal transsphenoidal resection. The lesion, its cystic portion and the capsule of the cyst removed and the infundibulum was preserved. Preoperative lumbar drain insertion and multilayer closure technique application was used to prevent postoperative cerebrospinal fluid leak. Lumbar drain was used for 5 days. Histopathological results revealed adamantinomatous craniopharyngioma.

Post-operative MRI studies showed infundibular preservation and normal sellar-suprasellar region. The patient developed temporary pituitary hypofunction due to minimal manipulation during surgery and corticosteroid replacement was necessary. She had transient diabetes insipidus (DI) and managed with desmopressin.

She did not develop any new neurological symptoms following surgery and was discharged home on postoperative day 7 .

In this case, the origin of craniopharyngioma from the outer layer of infundibulum, from pars tuberalis, is detected by endoscopically, with extended approach the tumor was resected gross totally with its cyst component from infundibulum. After opening of suprasellar dura, the content of the cyst was evacuated. The characteristic calcification pattern of craniopharyngioma was seen in the tumor. The cyst wall was dissected from optical chiasm and the superior part of the cyst wall was removed by gentle retraction, after visualizing the anterior communicating artery complex was divided from the tumor. After resection of tumor capsule, it was dissected and removed from the pars tuberalis, the outer layer of infundibulum which is the

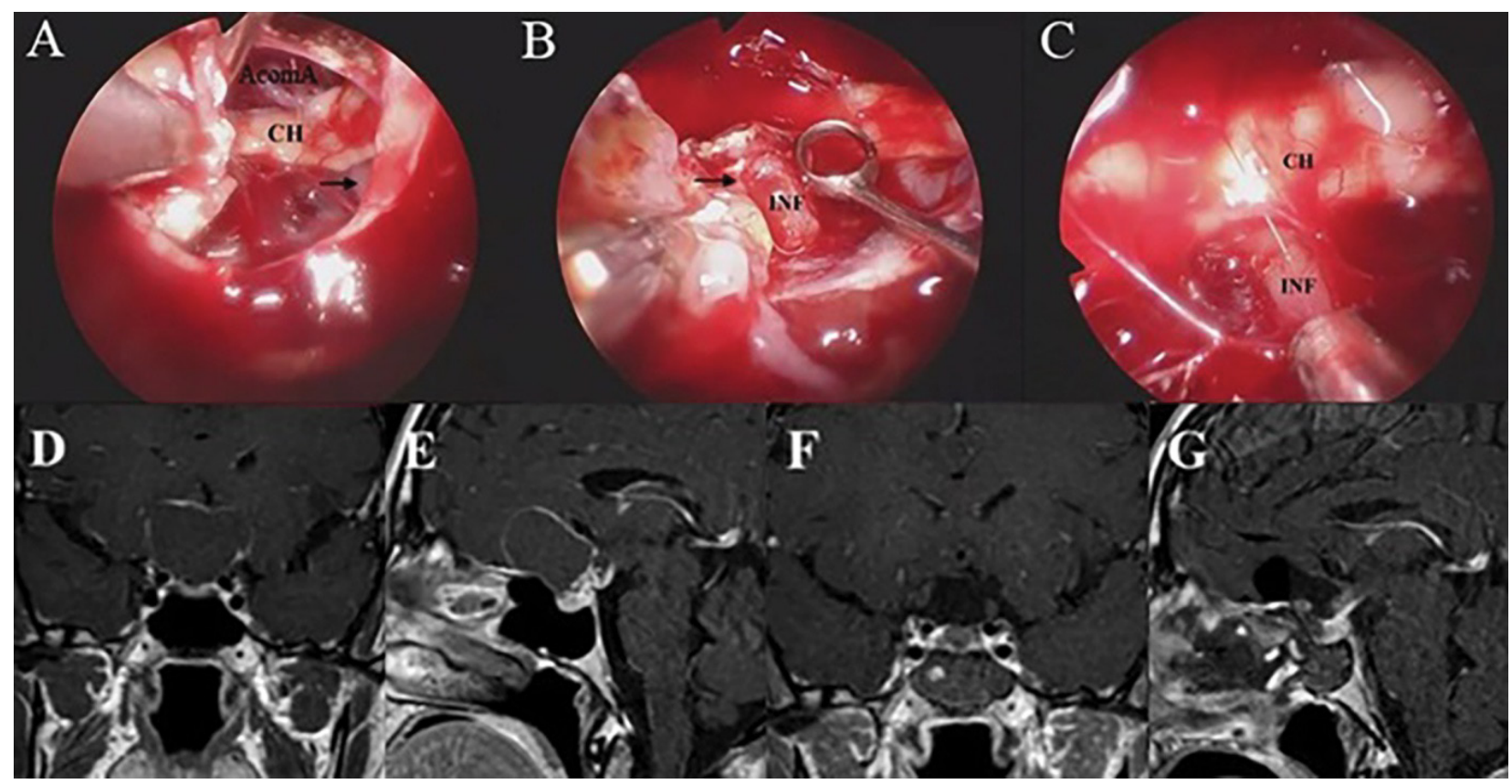

Figure 1: llustrative case 1 of infundibular craniopharyngioma with its cystic portion. A) Intraoperative photographs of superior part of cyst wall resection, optical chiasm, anterior communicating artery complex and black arrow which indicates supraclinoidal carotid artery; B) The black arrow in panel B indicates the origin of infundibular part of tumor and preserved infundibulum are shown; C) Preserved infundibulum after surgery and optical chiasm is seen; D and E) Preoperative coronal and sagittal contrast enhanced T1-weighted MR images, the lesion compresses the optic chiasm from the posterior and causes visual problems. Its infundibular part is seen clearly on sagittal plane; F and G) Postoperative coronal and sagittal contrast enhanced T1-weighted MR images, normal sellar and suprasellar region is shown.

AcomA Complex: Anterior communicating artery complex; $\mathrm{CH}$ : Optical chiasm; INF: Infundibulum. 
origin of this case. In this case, infundibulum and the pituitary arteries were preserved (Figure 1).

Preoperative and postoperative contrast enhanced T1-weighted MR images are shown (Figure 1).

\section{Case 2}

A 41-year-old female referred to our clinic by an endocrinologist. She presented with headache, polyuria, polydipsia, hypogonadism and somnolence (infundibulo-tuberal syndrome). On the admission, she was using drugs for central hypothyroidism and diabetes insipidus. Her physical examination had no abnormalities.

The patient was followed 6 months by endocrinology and neurosurgery clinics for her small solid infundibular lesion which was not considered as craniopharyngioma as the primary diagnosis, on her follow up, it was seen that the tumor was enlarged and the patient has started to have visual abnormalities, so the surgery decision was made.

Magnetic resonance imaging (MRI) revealed suprasellar mass lesion which was demonstrated as hyperintense on T1-weighted MR images, hypointense on T2-weighted MR images, it had solid component. Also it showed indentation to optic chiasm.

The patient underwent endoscopic endonasal transsphenoidal resection. The enlarged infundibulum was incised and the contents of the tumor were evacuated, then the infundibulum was dissected from the superior and inferior parts for total resection via extended endoscopic approach with image guided neuronavigation system. She had a lumbar drain placed intraoperatively and removed by post-operative day 5 . The diagnosis was histologically confirmed.

Post-operative MRI studies showed postoperative

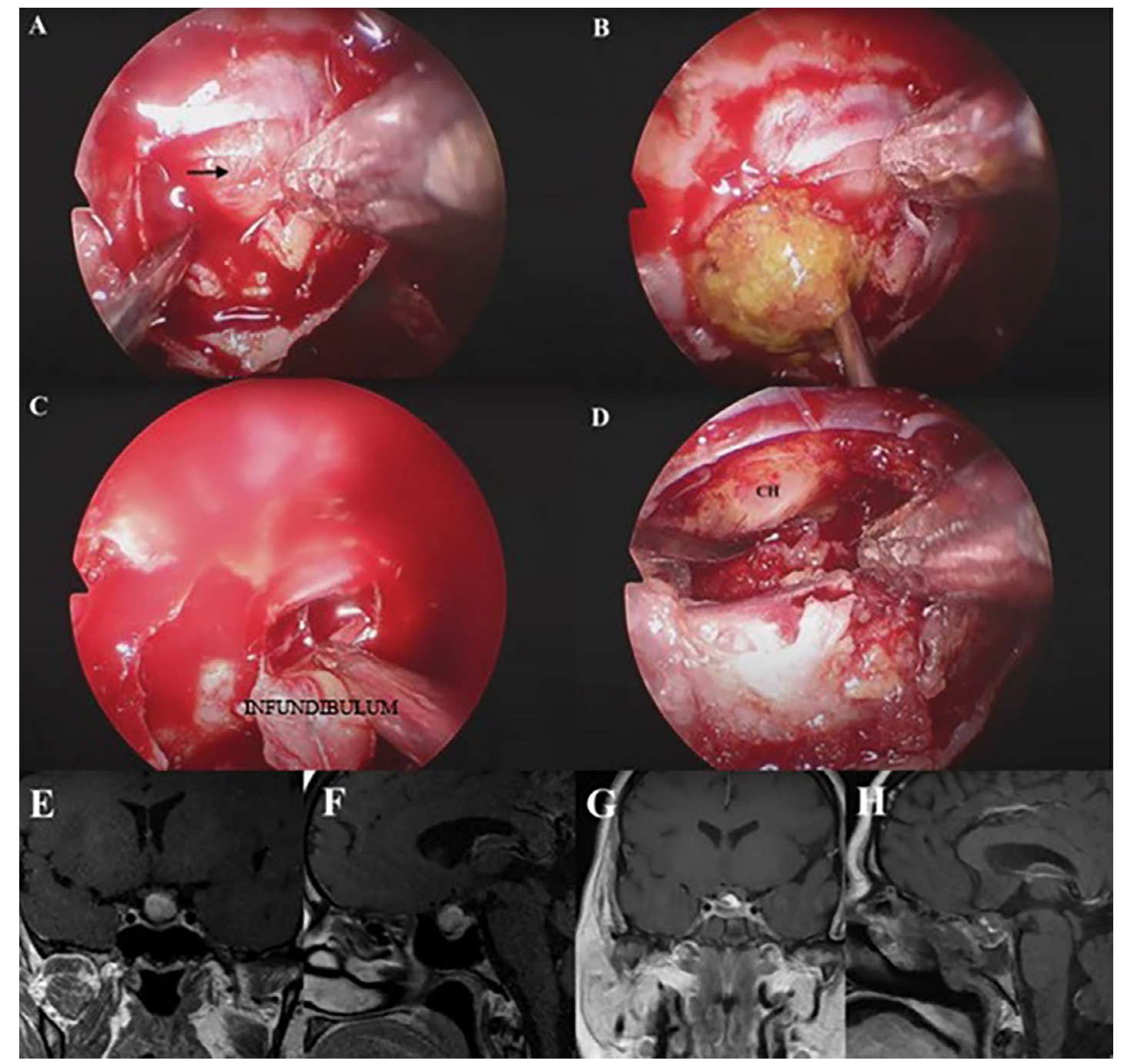

Figure 2: Illustrative case 2 of solid infundibular craniopharyngioma. A) Intraoperative photographs. The black arrow in panel A indicates that enlarged infundibulum; B) Evacuation of the craniopharyngioma content after opening of infundibulu; C) Infundibular tumor resection with infundibulum itself; D) Optic chiasm and operation site after infundibular resection; $\mathrm{E}$ and F) Preoperative coronal and sagittal contrast enhanced T1-weighted MR images demonstrated suprasellar mass lesion, which also involves infundibular region; $\mathrm{G}$ and $\mathrm{H}$ ) Postoperative coronal and sagittal contrast enhanced T1-weighted MR images show postoperative changes at sellar region.

TM: Tumor; $\mathrm{CH}$ : Optical Chiasm. 
changes at operation area and gross total resection was achieved.

The diabetes insipidus (DI) did not increase and the patient was discharged on corticosteroid supplementation, as well as desmopressin analogue therapy.

She was discharged home on postoperative day 6 .

In this case, the patient was followed for her small infundibular lesion first. After her tumor was enlarged to the median eminence, it was accepted as infundibulo-tuberal lesion and the surgery decision was made. After suprasellar opening, the infundibulum was seen to be very enlarged because of the tumor mass. The craniopharyngioma content was evacuated. The infundibular portion of tumor and itself was removed by surgical resection, and dissected from optical chiasm superiorly. The tumor mass was removed gross totally by extended approach and infundibulum sacrificed for total resection (Figure 2).

Preoperative and postoperative contrast enhanced T1-weighted MR images are shown (Figure 2).

\section{Discussion}

Craniopharyngiomas arise from squamous epithelial remnants of Rathke's pouch, originated from infundibulum-tuber cinerum and most of primary infundibular craniopharyngiomas grew along the axis of infundibulum [8]. Differential diagnoses of infundibular lesions are important for appropriate treatment. Infundibular lesions classified as neoplastic, inflammatory-infectious and congenital-developmental lesions [10]. Infundibular craniopharyngiomas are considered as neoplastic lesions.

With the involment of hypothalamus (tuber cinereum), upper neurohypophysis (median eminence) and infundibulum, the infundibulo-tuberal syndrome may occur which is characterized by the hypogonadism, obesity, diabetes insipidus and somnolence which can seen at infundibulo-tuberal lesions [7,11]. Also visual impairment is one the of the major presenting symptom and potential postoperative complication at infundibular craniopharyngiomas $[12,13]$. Lesions expanding within the $3^{\text {rd }}$ ventricle can also associate a hypothalamic syndrome includes psychiatric disturbances, memory Korsak off-like syndrome, and gait ataxia [14]. At our first case, the patient did not show typical infundibular syndrome because of the tumor's origin which was the outer layer of infundibulum, pars tuberalis, but the

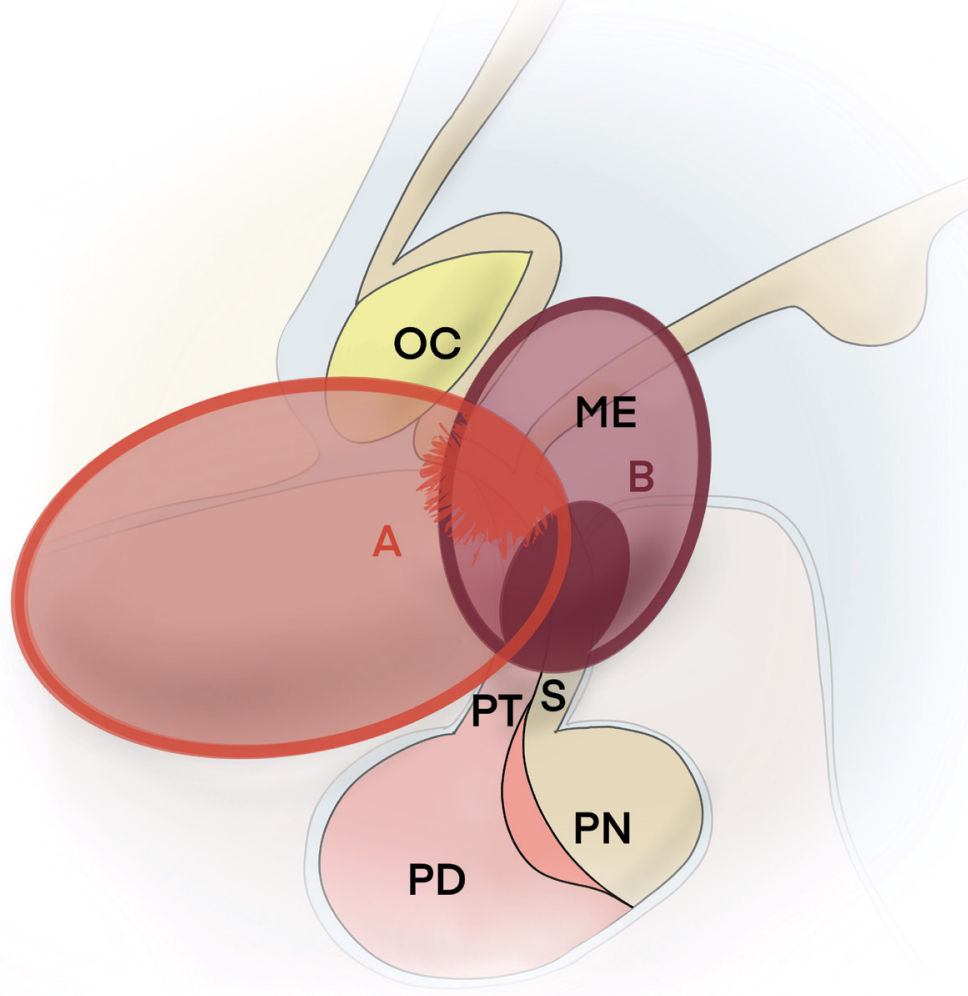

Figure 3: Illustrative drawing representing in sagittal section, structures involved in Case 1 and Case 2. A) Primary infundibular cystic craniopharyngioma, Case 1, which originates from the outer layer of infundibulum, pars tuberalis, also has cystic subfrontal extension; B) Primary infundibulo-tuberal craniopharyngioma, Case 2, which originates from infundibulum, after follow-up, enlarged to the median eminence.

OC: Optical Chiasm; ME: Median Eminence; S: Stalk; PT: Pars Tuberalis; PD: Pars Distalis; PN: Pars Nervosa. 
second one showed diabetes insipidus, hypogonadism and somnolence pre and postoperatively due to its infundibulo-tuberal involvement (Figure 3).

Identification of the tumor preoperatively is important for appropriate surgical approach and degree of resection. Endoscopic endonasal transsphenoidal approach is accurate and effective with higher resection rates for infundibular craniopharyngiomas, it enables in-line access, superior visualization and observation of the relationship with vital structures such as optical chiasm, hypothalamus and pituitary stalk [8]. The adherence pattern of infundibulo-tuberal lesions and those invading the $3^{\text {rd }}$ ventricle after breaking through the infundibulum is the crucial consideration, because of adhesion into the adjacent hypothalamus, determine both the high risk of surgical hypothalamic injury if the radical resection is attempted as well as a high recurrence rate, compared to lesions only adhered to the solid pituitary stalk and outer infundibulum [15]. At our first case because of the tumor's origin, outer layer of infundibulum, the risk of hypothalamic injury was less, because of that postoperatively hypothalamic functions were preserved after gross total tumor removal. But for second case despite maximal caution, with this high-risk adhesion to surrounding hypothalamus, hypothalamic sequelae was inevitable postoperatively.

In endoscopic approaches, total resection rates of the tumor depend on the infrachiasmatic corridors' limitations. Through the third ventricular floor, it can be surgically reached to the tumor. It increases surgical resection rates [12]. With these advantages, the preservation of pituitary stalk and infundibulum is possible, the recurrence rate and the risk of complications is lower with the experience because the anatomical structures could be better demonstrated and identified at extended endoscopic endonasal transsphenoidal approach. Hovewer, demonstration of the tumor's infundibular origin and growth pattern is very difficult, the most important feature of these two cases is that they definitely identified the origin, growth pattern and resection of the tumor from the infundibulum during the endoscopic endonasal transsphenoidal surgery. Endoscopic endonasal transsphenoidal approach can optimally assess the craniopharyngioma-hypothalamus boundary of adhesion, but despite our long experience, it cannot prevent hypothalamus damage when the lesion is infiltrating the adjacent hypothalamus.

Complete surgical resection is recommended for craniopharyngioma surgery. The first operation is critical for total resection because surgery in recurrent cases is more difficult than in primary cases due to adhesions in the surrounding structures. For large craniopharyngiomas, to protect the vital structures subtotal resection may be considered. The surgical approach is fundamental to demonstrate the vital structures and protect the normal anterior pituitary function. The preservation of pituitary stalk is also very important to avoid post-operative hypothalamicpituitary axis hypofunction which may require hormone replacement. At early postoperative period, hypothalamo-pituitary axis failure, stalk dysfunction (diabetes insipidus) may occur but there is a potential for recovery with time [1].

In this study, we presented primary infundibular cystic and infundibulo-tuberal craniopharyngioma of two cases which are very rare in our large craniopharyngioma case series [12]. In these two cases, the extended endoscopic endonasal transsphenoidal approach is used which provides preserving the pituitary stalk as much as possible and identification of the stalk from the tumor. If possible, the infundibulum should be preserved, but in infundibulotuberal craniopharyngioma cases, the infundibulum should be removed to prevent recurrence [12]. In these two cases, gross total resection is achieved and the patients were recovered. Total resection of the tumor was achieved in our first case, but in our second case, the infundibulum was sacrificed to ensure total resection.

\section{Conclusion}

Identification and surgical approach of primary infundibular and infundibulo-tuberal craniopharyngiomas are very different from other types of craniopharyngiomas because of their origin, growth pattern and clinical features. Endoscopic endonasal transsphenoidal approach is accurate and effective choice with the chance of preservation of pituitary stalk and normal anterior pituitary functions. Also with the experience, it enables low recurrence rate and decreasing risk of complications. But it cannot prevent hypothalamus damage when the lesion is infiltrating the adjacent hypothalamus as seen in infundibulo-tuberal craniopharyngiomas. Preoperative and postoperative demonstration and presentation of the tumor is very important in order to increase the amount of surgical resection, reduce the complications, protect the infundibulum and prevent hypothalamic injury.

\section{Disclosures}

The authors report no conflict of interest concerning the materials and methods used or the findings specified in this study.

\section{Acknowledgments}

Preparation for publication of this article is partly supported by Turkish Neurosurgical Society.

\section{Funding}

This research did not receive any specific grant from funding agencies in the public, commercial, or not-forprofit sectors.

\section{References}

1. Figueiredo EG, Welling LC, de Faria JW, Teixeira MJ 
(2011) Pituitary stalk craniopharyngioma. BMJ Case Rep.

2. Jane JA, Laws ER (2006) Craniopharyngioma. Pituitary 9: 323-326.

3. Kassam AB, Gardner PA, Snyderman $\mathrm{CH}$, Carrau RL, Mintz $\mathrm{AH}$, et al. (2008) Expanded endonasal approach, a fully endoscopic transnasal approach for the resection of midline suprasellar craniopharyngiomas: A new classification based on the infundibulum. J Neurosurg 108: 715-728.

4. Pascual JM, Gonzalez-Llanos F, Barrios L, Roda JM (2004) Intraventricular craniopharyngiomas: Topographical classification and surgical approach selection based on an extensive overview. Acta Neurochir (Wien) 146: 785-802.

5. Pascual JM, Prieto R, Carrasco R (2011) Infundibulo-tuberal or not strictly intraventricular craniopharyngioma: Evidence for a major topographical category. Acta Neurochir (Wien) 153: 2403-2425.

6. Unal O, Cırak S, Bal E (2021) MRI findings of infundibular craniopharyngioma: Two case reports. Acta Oncologica Turcica.

7. Castro-Dufourny I, Carrasco R, Prieto R, Pascual JM (2015) Infundibulo-tuberal syndrome: The origins of clinical neuroendocrinology in France. Pituitary 18: 838-843.

8. Tang B, Xie SH, Huang GL, Wang ZG, Yang L, et al. (2019) Clinical features and operative technique of transinfundibular craniopharyngioma. J Neurosurg 14: 1-10.
9. Yasargil MG, Curcic M, Kis M, Siegenthaler G, Teddy PJ, et al. (1990) Total removal of craniopharyngiomas. Approaches and long-term results in 144 patients. J Neurosurg 73: 3-11.

10. Rupp D, Molitch M (2008) Pituitary stalk lesions. Curr Opin Endocrinol Diabetes Obes 15: 339-345.

11. Castro-Dufourny I, Carrasco R, Prieto R, Barrios L, Pascual JM (2015) The infundibulo-tuberal syndrome caused by craniopharyngiomas: Clinicopathological evidence from an historical French cohort (1705-1973). Pituitary 18: 642-657.

12. Ceylan S, Caklili M, Emengen A, Yilmaz E, Anik Y, et al. (2021) An endoscopic endonasal approach to craniopharyngioma via the infrachiasmatic corridor: A single center experience of 84 patients. Acta Neurochir (Wien) 163: 2253-2268.

13. Tang B, Xie SH, Xiao LM, Huang GL, Wang ZG, et al. (2018) A novel endoscopic classification for craniopharyngioma based on its origin. Sci Rep 8: 10215.

14. Pascual JM, Prieto R, Rosdolsky M (2021) Craniopharyngiomas primarily affecting the hypothalamus. Handb Clin Neurol 181: 75-115.

15. Prieto R, Pascual JM, Hofecker V, Winter E, CastroDufourny I, et al. (2020) Craniopharyngioma adherence: A reappraisal of the evidence. Neurosurg Rev 43: 453-472. 